\title{
PESQUISADOR E CRIANÇA: DIALOGISMO \\ E ALTERIDADE NA PRODUÇÃO DA INFÂNCIA CONTEMPORÂNEA
}

RITA MARISA RIBES PEREIRA

Professora Adjunta da Faculdade de Educação da Universidade

do Estado do Rio de Janeiro

ritaribes@uol.com.br

\section{RAQUEL GONÇALVES SALGADO}

Professora Adjunta do Departamento de Psicologia da

Universidade Federal de Mato Grosso - Campus Rondonópolis

ramidan@terra.com.br

\section{SOLANGE JOBIM E SOUZA}

Professora do Departamento de Psicologia da Pontifícia Universidade Católica do Rio de Janeiro e da Faculdade de Educação da Universidade do Estado do Rio de Janeiro soljobim@uol.com.br

\section{RESUMO}

O propósito deste artigo é analisar o ato de pesquisar com crianças e elaborar uma perspectiva crítica da produção da subjetividade na relação entre adultos e crianças na contemporaneidade. A teoria da linguagem de Mikhail Bakhtin serviu de base para discutir o complexo tema da alteridade no âmbito da relação pesquisador-criança. A ampliação do debate sobre a relação entre adultos e crianças em face dos desafios da cultura do consumo e da sociedade da informação foi considerada uma alternativa metodológica promissora na busca de soluções coletivas para as questões que se colocam no campo educacional no mundo de hoje.

PESQUISA - INFÂNCIA - LINGUAGEM - CULTURA

\section{ABSTRACT}

RESEARCHER AND CHILD: DIALOGISM AND OTHERNESS IN THE PRODUCTION OF CONTEMPORARY CHILDHOOD. This paper aims to analyze the research with children and to elaborate a critical approach about subjectivity production between adults and children on contemporaneity. Mikhail Bakhtin's Theory of Language was used as the theoretical basis to discuss the complex subject of dialogism and otherness in the relationship between researcher and child during the field work. Our proposal was to enlarge the discussion about this relationship, taking into account the consumer culture and the informational society, as a way of trying to overcome the educational challenges nowadays.

RESEARCH - CHILDHOOD - LANGUAGE - CULTURE 
Tudo o que me diz respeito, a começar por meu nome, e que penetra em minha consciência, vêm-me do mundo exterior, da boca dos outros (da mãe, etc.), e me é dado com a entonação, com o tom emotivo dos valores deles. Tomo consciência de mim, originalmente, através dos outros: deles recebo a palavra, a forma e o tom que servirão para a formatação original da representação que terei de mim mesmo

(Mikhail Bakhtin, 2003, p.373)

De acordo com esta epígrafe, a produção da consciência de si, para Mikhail Bakhtin, se dá a partir das relações que se estabelecem no campo social, interações, portanto, que acontecem na e pela linguagem, entre o eu e o outro. Ao adotarmos esse enfoque teórico como ponto de partida de nossas investigações, entendemos que pesquisar a infância exige uma tomada de consciência do lugar social que a criança ocupa na relação com o adulto pesquisador.

Nessa abordagem, dialogismo e alteridade são tomados como princípios epistemológicos fundamentais, presentes em todo o processo de pesquisa. $O$ pesquisador vai agregando as diferentes vozes que surgem ao longo da caminhada, sistematizando o acontecimento da pesquisa em um novo texto. Ao analisar a especificidade das ciências humanas, Bakhtin diz:

...estamos interessados na especificidade do pensamento das ciências humanas, voltado para pensamentos, sentidos e significados dos outros, etc., realizados e dados ao pesquisador apenas sob a forma de texto. Independentemente de quais sejam os objetivos de uma pesquisa, só o texto pode ser o ponto de partida ( $p$. 308). [E conclui:] Onde não há texto não há objeto de pesquisa e pensamento (p. 307). O texto é o dado (realidade) primário e o ponto de partida de qualquer disciplina nas ciências humanas. (p. 319)

Este artigo tem como tema o próprio ato de pesquisar com crianças, admitindo que o acontecimento da pesquisa cria possibilidades de fazer revelações sobre as concepções de infância presentes no contexto cultural mais amplo. Assim, entendemos a pesquisa como abarcando simultaneamente um pensa- 
mento sobre o mundo e um pensamento no mundo. Ou seja, participamos de momentos diferenciados na produção do conhecimento, segundo a concepção de Bakhtin. Por um lado, temos o pensamento que procura abarcar o mundo, por outro, o pensamento que sente a si mesmo no mundo (como parte dele). Com isso, a pesquisa pode ser vista simultaneamente como acontecimento no mundo e como um modo de participação nele.

Tendo como base essas reflexões epistemológicas, apresentamos algumas questões como ponto de partida: o que pensamos sobre a infância e o que a torna uma categoria peculiar para interlocução? Que diálogos e que relações de reciprocidade se estabelecem no contexto da pesquisa com as crianças? Como as crianças constroem a visão que têm de si e dos outros no contexto da entrevista? Como o pesquisador se reporta ao universo de experiências da infância em um mundo regido pela cultura de massa e a sociedade da informação?

Questões como estas surgiram e estão sempre presentes em nosso trabalho de pesquisa com crianças'. E foi em torno delas que construímos o eixo reflexivo do presente artigo.

I. Os diálogos entre crianças e adultos transcritos neste artigo foram extraídos do acervo do Grupo Interdisciplinar de Pesquisa da Subjetividade, do Departamento de Psicologia da Pontifícia Universidade Católica do Rio de Janeiro - PUC-Rio -, e fazem parte de uma pesquisa sobre a relação com a mídia televisiva realizada junto a crianças de 5 e 6 anos que frequentavam uma unidade de educação infantil do Serviço Social do Comércio - Sesc - na cidade do Rio de Janeiro. A pesquisa de campo transcorreu durante um ano letivo, com encontros semanais de quatro horas de duração. A abordagem metodológica consistiu em oficinas destinadas a discutir as experiências com a mídia televisiva a partir da exibição de programas de diversos gêneros e contou com a participação das crianças e das professoras em diálogo com as pesquisadoras. Estas promoveram ainda reuniões com pais sobre o tema das relações das crianças com a mídia no espaço do lar, com o objetivo de registrar depoimentos sobre as suas atitudes em relação ao comportamento dos filhos. Além das gravações em áudio, utilizou-se o recurso do vídeo, para que, posteriormente, as crianças refletissem junto com os pesquisadores sobre as cenas em que apareciam brincando e conversando com eles, com as professoras e com os colegas. Nossa intenção, ao apresentar neste artigo extratos das entrevistas gravadas, é mostrar como o espaço da pesquisa pode ser encarado como um espaço de produção de linguagem, onde se travam disputas, acordos e negociações sobre os modos de ser e existir no mundo contemporâneo. Os sentidos produzidos a partir dos diálogos nas oficinas sobre as relações das crianças com a televisão não se esgotam no momento de realização da pesquisa de campo, e nem pretendem ser conclusivos, mas sim instigar novos questionamentos e indagações sobre o ato de pesquisar com as crianças a produção subjetiva no mundo contemporâneo. 


\section{MIKHAIL BAKHTIN E A PESQUISA EM CIÊNCIAS HUMANAS E SOCIAIS}

Para Mikhail Bakhtin, toda produção de conhecimento no campo das ciências humanas é um trabalho de "compreensão respondente", ou seja, uma tensão permanente entre o eu o e o outro na qual o pesquisador e seus interlocutores se implicam e se afetam incessantemente. Essa compreensão pressupõe diálogo e uma constante negociação de sentidos. Perguntas e respostas, para Bakhtin, não são categorias lógicas, mas acontecimentos que estão na vida, no campo das interações entre pessoas.

Assim, a entrevista com crianças no âmbito da pesquisa pode ser vista também como uma espécie particular de acontecimento na vida, onde a compreensão dos temas em pauta se dá a partir de confrontos de ideias, negociação de sentidos possíveis de serem apresentados. Por isso, Bakhtin admite ser impossível qualquer compreensão sem julgamento de valor. Para ele não se pode separar compreensão e avaliação, pois se trata de momentos simultâneos de um ato único: "o sujeito da compreensão não pode excluir a possibilidade de mudança e até de renúncia aos seus pontos de vista e posições já prontos. No ato de compreensão desenvolve-se uma luta cujo resultado é a mudança mútua e o enriquecimento" (Bakhtin, 2003, p. 378). E acrescenta:

O sentido é potencialmente infinito, mas pode atualizar-se somente em contato com outro sentido (do outro), ainda que seja com uma pergunta do discurso interior do sujeito da compreensão. Ele deve sempre contatar com outro sentido para revelar os novos elementos da sua perenidade (como palavra revela os seus significados somente no contexto). Um sentido atual não pertence a um (só) sentido mas tão somente a dois sentidos que se encontraram e contataram. Não pode haver "sentido em si" ele só existe para outro sentido, isto é, só existe com ele. Não pode haver um sentido único, ele está sempre situado entre os sentidos, é um elo na cadeia dos sentidos, a única que pode existir realmente em sua totalidade. Na vida histórica essa cadeia cresce infinitamente e por isso cada elo seu isolado se renova mais e mais, como que torna a nascer. (p. 382)

Concluímos com Bakhtin que o dialogismo é a base da constituição do sujeito e do conhecimento no campo das ciências humanas. Desse modo, não há um único ser humano cuja condição de humanidade não advenha da sua 
interlocução com os demais, dado que seu nascimento é dotado de significados antecipadamente atribuídos e que toda sua existência será marcada pelo modo como dará continuidade a essa interlocução.

O conceito de dialogismo na obra de Bakhtin não pode ser pensado à parte da concepção de alteridade. Ressalte-se que a alteridade aqui não se limita à consciência da existência do outro, nem tampouco se reduz ao diferente, mas comporta também o estranhamento e o pertencimento. $\bigcirc$ outro é o lugar da busca de sentido e da condição de existência e, simultaneamente, o lugar da incompletude e da provisoriedade. Essa perspectiva interroga e traz à tona o inacabamento permanente do sujeito, ou melhor, do vir-a-ser da condição do homem no mundo (Freitas et al., 2007).

Assumir o dialogismo e a alteridade como marcas das relações estabelecidas no contexto da pesquisa significa, portanto, buscar o encontro com o outro e compartilhar experiências, conhecimentos e valores que se alteram mutuamente. Nessa abordagem teórica, o outro deixa de ser uma realidade abstrata a ser definida e traduzida por um conceito. Em outras palavras, o sujeito da pesquisa é visto como alguém cuja palavra se confronta com a do pesquisador, refratando-a e exigindo-Ihe resposta. Em contrapartida, a palavra do pesquisador recusa-se a assumir a aura de neutralidade imposta pelo método e integra-se à vida, participando das relações e das experiências, muitas vezes contraditórias, que o encontro com o outro proporciona.

Com base nessa abordagem, entendemos a pesquisa com a criança em um contexto marcado por um processo de alteridade mútua, em que adultos e crianças, nos modos como cada um contempla e altera o olhar que vem do outro, definem suas experiências (Souza, Castro, 1998).

Na perspectiva dialógica e alteritária, o processo de pesquisa configura-se como um acontecimento no mundo que se efetiva entre sujeitos. $O$ conhecimento, construído no ato de pesquisar, mais do que uma reflexão sobre a realidade investigada, remete a uma reflexão situada no contexto em que o pesquisador está inserido, do qual participam muitas consciências (Bakhtin, 2003).

Tratando-se de pesquisa com crianças, esse modo de produzir conhecimento se traduz no processo de pesquisar com o outro - a criança -, e não mais em pesquisar sobre ela, buscando uma definição sobre a infância que silencia diante do confronto e das tensões entre as imagens que crianças e adultos constroem de si e do outro (Souza, 2005). 
Além disso, dado que o conhecimento é provocado por uma pergunta, ele não pode se constituir na ausência de resposta. E, para Bakhtin, não há resposta que não gere uma nova pergunta. Perguntas e respostas compõem a engrenagem que movimenta a construção do sentido e do conhecimento na pesquisa. Entretanto, a função da pergunta e da resposta no contexto da entrevista na pesquisa em ciências humanas assume, para Bakhtin, uma especificidade que deve ser destacada.

Pergunta e resposta não são relações (categorias) lógicas; não podem caber em uma só consciência (una e fechada em si mesma); toda resposta gera uma nova pergunta. Perguntas e respostas supõem uma distância recíproca. Se a resposta não gera uma nova pergunta, separa-se do diálogo e entra no conhecimento sistêmico, no fundo impessoal. (Bakhtin, 2003, p. 408)

Ao assumirmos a teoria da linguagem de Bakhtin como fundamento de nossas preocupações metodológicas no uso da entrevista com crianças, o ato mesmo de entrevistar e suas consequências interpretativas se modificam radicalmente. Aqui, o resultado da entrevista não é a fala da criança tomada isoladamente, mas é a cena dialógica que se estabelece entre o pesquisador e a criança que produz sentidos, acordos e negociações sobre um determinado assunto em um contexto definido por esse ato de falas recíprocas.

No diálogo com as crianças, a alternância de perguntas e respostas, a perplexidade diante dos atos e discursos alheios, assim como os pontos de vista e valores que se desnudam no encontro com o outro fazem da pesquisa um processo vivo de construção de conhecimento e sentidos sobre os modos de perceber e significar a cultura contemporânea.

A relação alteritária entre crianças e adultos não se constitui apenas como um objeto de estudo, mas como um acontecimento que adquire corpo e vida no ato de pesquisar e compreender o outro. $\bigcirc$ adulto-pesquisador, nesse contexto, não apenas pergunta para obter respostas que atendam aos objetivos definidos de antemão, mas, ao perguntar e também responder, ele se posiciona como um outro, que, do lugar de adulto, traz perspectivas e valores diversos sobre as experiências compartilhadas com as crianças. 


\section{PERSPECTIVAS DE ALTERIDADE NA MITOLOGIA, NA VIDA E NA PESQUISA}

Marilia Amorim (200I), ao se remeter às pesquisas de Jean-Pierre Vernant $(1985,2005)$, problematiza o complexo tema da alteridade propondo novos sentidos para esta reflexão. Ela destaca três figuras fundamentais da mitologia grega: Górgonas, Dionísio e Ártemis - respectivamente Medusa, Baco e Diana, na mitologia romana.

Na primeira figura - Górgonas - o outro é um outro absoluto, impossível de se olhar nos olhos, pois rejeita toda ideia de duplicidade. Se olhado nos olhos, transforma quem o olha em estátua de sal ou de pedra, metáfora do aniquilamento - um outro a ser devorado. Ainda que o mito se mantenha em aberto e alimente nossas conjecturas acerca da personificação do medo, permanece inquebrantável a necessidade de apagamento do outro como forma de aplacar o medo, seja pela indiferença do não-olhar, seja pela imobilização em estátua de pedra.

A segunda figura é Dionísio, o deus que experimenta ser um outro sendo ele mesmo - um outro adormecido que, quando desperto, é por demais estranho. Dois modos de ser que nunca se encontram. É um "estrangeiro do interior", é a alteridade próxima.

Ele representa aquilo que, no interior da própria vida, nos desenraiza de nossa existência cotidiana, do curso normal das coisas, e de nós mesmos. O disfarce, a máscara, a embriaguez, o jogo, o transe, o delírio do êxtase, todas essas são vias de acesso ao estranhamento. Dionísio nos ensina ou nos impõe o tornar-se outro, diferente daquilo que somos normalmente. A fazer, a partir dessa vida mesmo, uma experiência de evasão que leva a uma experiência desconcertante. (Amorim, 200 I, p. 52)

Enquanto Dionísio apresenta o estranho que vem do interior, Ártemis, a terceira figura, é a deusa que vem do exterior - é de origem bárbara - e "representa a capacidade implícita em uma cultura de integrar aquilo que lhe é estrangeiro. A partir dela, todos aqueles que eram de início diferentes, opostos e mesmo inimigos poderão ter uma vida comum no contexto de um grupo unido". É a construção do que é o seu "mesmo" tendo incorporado o que the é estranho (Amorim, 200 I, p. 53). 
Se em Dionísio o mesmo e o estranho não existem em simultaneidade, em Ártemis é essa simultaneidade que a caracteriza. Deusa das feras, Ártemis exerce a arte da caça, cuja disciplina expõe os limites e a transitoriedade entre o selvagem e o civilizado. Deusa das crianças, delas cuida até que se mostrem aptas a encarar a idade adulta. Deusa dos partos, vela os limites extremos da integração da alteridade - o adulto/mãe que se encontra com o extremamente outro ainda há pouco não visto desta maneira.

Ártemis habita as fronteiras. Ela está ali onde se atravessa em direção ao país do Outro e por onde se retorna. Garantia de demarcação e de interpenetração entre as diferenças, permite a passagem de um sentido para o outro, produzindo sempre transformações, mas sem que os limites sejam apagados. As zonas limítrofes são aquelas em que o contato com o Outro se faz; são os confins da cidade e do mundo civilizado. (Amorim, 200 I, p. 53-54)

A dimensão alteritária da experiência humana, representada no âmbito da mitologia pelas figuras de Górgonas, Dionísio e Ártemis, será aqui tomada como referência alegórica. $\bigcirc$ que estas imagens mitológicas sugerem como elementos de reflexão para uma compreensão crítica do encontro do pesquisador e seu outro?

A abordagem de Marília Amorim (200l) estimula uma reflexão sobre a experiência da alteridade no contexto da pesquisa, e sugere uma interpretação que nos permite observar as tensões dialógicas que se constituem no momento do encontro do pesquisador com seu outro, definindo os limites das interpretações de sentidos que se constituem nesse momento específico.

Nosso objetivo, tendo como cenário o encontro do pesquisador com a criança, é provocar uma atitude reflexiva sobre os lugares sociais que ambos foram negociando ao longo do processo, criando narrativas que, em um certo sentido, aludem aos embates entre os modos de ver o outro e a si mesmo no contexto da pesquisa. Entendemos assim que o outro, na relação entre pesquisador e criança, ainda que reconhecidamente outro, pode, entre os mais diversos aspectos, apresentar-se como ameaça, como indagação, como procura ou complemento.

Cabe ao pesquisador ampliar seus modos de ver e interpretar o que cada conjunto de narrativas revela sobre a relação do adulto com a criança no contexto onde se desenvolve a entrevista propriamente dita. 


\section{GÓRGONAS, DIONÍSIO E ÁRTEMIS: IMAGENS ALEGÓRICAS DA INFÂNCIA E DA VIDA ADULTA}

Como construímos o diálogo com as crianças? Que perguntas surgem e que respostas esperamos? Entre perguntas e respostas, o que dizemos sobre nós mesmos e uns dos outros? Apresentaremos a seguir situações do trabaIho de campo a fim de explicitar a dimensão alteritária que se faz presente no contexto da pesquisa.

Se, à primeira vista, a criança aparece como o interlocutor privilegiado a ser investigado pelo pesquisador, constatamos também que o pesquisador, ao longo da entrevista, se configura como alguém que pode ser interpelado pela criança. Observamos que na visão das crianças, nossa identidade de pesquisadoras foi sendo construída como "perguntadoras": "Vocês são repórteres?"; "Nossa! Você fala demais! Você faz muita pergunta!"; "Parece minha mãe!". O corolário dessa nomeação se explicita na fala de Carolina: "Sabe o que você é? Você é fofoqueira. Porque você fala demais. Você pergunta demais."

Embora nesse diálogo sejam demarcados os lugares do adulto (aquele que pergunta) e o da criança (aquela que responde), em outras situações esses lugares, no interior do discurso, se alteram. Foi o que aconteceu, por exemplo, quando as crianças reivindicaram o uso do gravador como forma de brincadeira. Desse contexto extraímos a seguinte cena:

Bruno (5): Eu também quero falar.

Karine (5): Eu também quero falar.

Rita (pesquisadora): Então tem que falar alguma coisa.

Karine: Então eu vou falar alguma coisa.

Rita: O que você vai falar?

Karine: É... Tem que escovar os dentes todo dia.

Rita: Tem que escovar os dentes todo dia?

Karine: Porque...

Bruno: Vamos fazer assim... agora eu quero falar...

Karine: Quando eu tiver com seis anos eu vou perder meu dente...

Bruno: Eu quero falar, eu quero falar. Tem que varrer a casa todos os dias.

Karine: E cuidar dos brinquedos.

Rita: Tem que guardar os brinquedos? 
Bruno: E tem que escovar os dentes todos os dias também.

Rita: É mesmo?

Bruno: E tem que molhar a planta todo dia também.

Rita: Molhar a planta também?

Amanda (5): É. Tem que alimentar a plantinha senão ela vai morrer.

Rita: Ah, tá certo, é.

Amanda: E tem que escovar todo... o dente todo dia, o seu dentinho. Senão, quando ele cair, ele vai ficar amarelo.

Bruno: Tem que escovar o dente todo dia.

Amanda: De manhã, vai ter que escovar. No almoço. Depois do almoço, quer dizer, é, de noite, antes de dormir.

Bruno: E tem que fazer dever de casa todo dia. Depois do jantar. ${ }^{2}$

O desejo de falar ao gravador exige que Bruno, Karine e Amanda construam uma identidade que espelhe as expectativas do adulto e relação às crianças. A sutil escolha de um tema que fosse considerado "legítimo" surge como garantia de uso do gravador. Podemos nos indagar o que levou à escolha desse tema para dar conteúdo a uma conversa, que, embora se desenrolasse entre eles, marcava a presença do adulto como receptor privilegiado.

$\mathrm{Na}$ cena que relatamos, a presença do adulto define para a criança comportamentos, atitudes esperadas, ou seja, as crianças mostram como deve ser, o que é correto e o que é errado. As crianças brincam revelando aquilo que sabem que os adultos esperam delas. Desse modo, falam de si, mas, principalmente, do modo como compreendem as expectativas dos adultos em relação a elas.

Nesse jogo de espelhos em que nos reconhecemos e às vezes até nos surpreendemos com as descobertas mútuas, nossas compreensões do que é

2. Esse relato faz parte dos registros do diário de campo. Refere-se à percepção, por parte das crianças, da importância dada pelas pesquisadoras à gravação de suas falas. Num primeiro momento do trabalho de campo, a inserção do gravador, aparelho até então desconhecido pelas crianças, provocou nelas um imenso desejo de falar e de escutar sua voz gravada. Essa experiência gerou a produção de uma discursividade espontânea por parte das crianças, ao mesmo tempo atravessada pelos sentidos e pelos lugares sociais que estávamos construindo na relação de pesquisa. Chamou-nos a atenção a intensidade com que as crianças recorreram a temas que revelavam sua percepção daquilo que os adultos esperam delas e como esse discurso, em forma de jogo, é trazido à cena para garantir o uso do gravador. 
a infância e a vida adulta se constituem em permanente negociação. Se, por um lado, a conformidade infantil ao discurso do adulto revelou em algumas situações uma indiscutível tutela, por outro, constatou-se uma atitude que mostrava uma outra face da infância, em que a autonomia da criança diante do discurso do adulto chegava a ser desconcertante ou mesmo estranha às expectativas de uma infância idealizada e sob controle.

Esse estranhamento do adulto em relação à criança ganha visibilidade na fala de um pai ao relatar, com certa desconfiança, as preferências, o gosto e as atitudes da filha:

E ela é uma peruazinha. Adora SBT, novelinha do SBT, Xuxa, qualquer coisa que tiver de consumo é com ela mesmo. Aí tem que ter chaveiro das Meninas Super-Poderosas, adora! Adora o Dexter, tudo que é desenho. Mas ela gosta não é só desses filmes específicos. Eu queria até que ela gostasse mais do Sítio do Pica-pau Amarelo [riso geral]. Mas, como ela é uma consumista, o que é que eu vou fazer? É, tem que ter produto, tem que ter alguma coisa pra ela saber que consegue. ${ }^{3}$

Nas duas situações reproduzidas, vale destacar os processos de subjetivação em jogo. No diálogo entre as crianças, elas buscam legitimar seu discurso conformando-o às expectativas dos adultos. Já no relato do pai, o distanciamento do comportamento da filha mostra que outras narrativas estão igualmente presentes no campo social, e ganham um espaço cada vez mais expressivo.

Os discursos da mídia direcionados ao público infantil produzem sentidos compartilhados entre as crianças, criando um universo semântico que apresenta particularidades, algumas consideradas muito distantes das experiências culturais vividas diretamente no interior da família.

A partir de um olhar atento para as conversas entre adultos e crianças, algumas questões se colocam, tais como: Qual o lugar do adulto no atual dis-

3. Este relato, assim como o seguinte, foi extraído dos registros de reunião feita com os pais das crianças para a apresentação da pesquisa. Sua reprodução aqui tem o propósito de problematizar os modos como os adultos se envolvem (ou não) na educação das crianças, entendendo que essa relação de alteridade é atravessada por diferentes discursos institucionais - escola, família, mídia, etc. -, bem como pela memória da infância que constitui a experiência do adulto. 
curso que a mídia direciona às crianças? Como a imagem da criança e a imagem do adulto são retratadas pela mídia? Em que adultos e crianças concordam com essas imagens ou as contestam? O que a família e a escola têm a dizer sobre as representações culturais da infância e da vida adulta presentes nos programas infantis, na publicidade e nos meios de comunicação em geral?

Nosso objetivo, ao apresentar esse elenco de perguntas, não é certamente dar as respostas ao leitor, mas criar compromissos entre pais, professores, profissionais que lidam com a infância e a juventude para juntos encontrarmos as respostas que precisam ser enfrentadas coletivamente. A preocupação é criar estratégias para não cairmos nas ciladas da omissão e do medo e sermos seduzidos pela figura das Górgonas.

Adultos e crianças na contemporaneidade correm o risco de evitar olhar uns para os outros, ou porque não suportariam a revelação da total duplicidade, ou porque temem enfrentar suas diferenças. Em contrapartida, à maneira de Dionísio, o adulto confrontado com a experiência da criança pode vivenciar a alteridade de seu próprio interior. Isto porque a criança representará sempre um outro; mas esse outro não é apenas estranho, uma vez que também o adulto já foi criança um dia, e essa experiência, transformada em memória, é inalienável.

Desse modo, a infância, como memória, permanece interiorizada, tal qual a alteridade vivida por Dionísio, o deus que experimenta ser um outro sendo ele mesmo. $\bigcirc$ adulto torna-se outro ao rememorar com a ajuda da criança experiências passadas que se atualizam. É disso que nos fala Isabel, ao observar sua filha Luana.

A Luana [4 anos] é uma peruazinha. Eu às vezes me preocupo. É demais. Só sai pra rua se passar batom. E quando não passa diz que está feia. Eu fico vendo. Às vezes brigo feio. A gente tem que dar limites, que é pra não cair nessas vaidades bobas. Mas, às vezes, no meio da briga, é engraçado, eu me lembro que quando eu era criança eu fazia birra com a minha mãe toda vez de cortar o cabelo, que eu queria um corte que era moda, com um franjão. E minha mãe dizia que atrapalhava os olhos e ia prejudicar na escola. Mas eu queria porque queria. Aí eu penso nisso e vejo a Luana me tirando a paciência e aí eu relevo. Também é bom a gente ter opinião, mas tem que saber compreender o que é certo. Dos dois lados, das crianças e das mães. 
A cena descrita por Isabel se vale da rememoração como instrumento para melhor compreender a filha, mas esconde nas entrelinhas a perspectiva trazida por Ártemis, deusa mitológica da caça, deusa da procura. Visando a unidade na diversidade, Ártemis sugere que só nos reconhecemos adultos ou crianças na presença uns dos outros. Ela permite a passagem de um sentido para o outro, produz transformações, sem deixar que os limites e as demarcações sejam desfeitos. As zonas limítrofes evidenciam o necessário contato da diferença em relação ao outro.

Crianças e adultos têm diferentes pontos de vista e é dessa diferença que se constitui a realidade em que se inserem e o modo como se revelam como sujeitos únicos no mundo.

\section{PESQUISA INTERVENÇÃO E PRODUÇÃO DA SUBJETIVIDADE}

Ao longo da pesquisa, constatamos que as crianças, em seus discursos e brincadeiras, revelavam a compreensão que tinham de si, dos outros e do mundo social, mostrando como as nuanças da vida infantil se manifestam no mundo de hoje. Suas experiências e suas falas excediam, muitas vezes, aquilo que nossos referenciais teóricos e nossas singulares memórias de infância conseguiam abarcar, principalmente ao expressar com naturalidade opiniões relacionadas às temáticas mais comuns ao mundo do adulto - trabalho, violência, sexualidade, erotização, etc.

Com certa perplexidade, indagávamos a pertinência desses temas ao universo infantil e obtínhamos como resposta a recusa por parte das crianças de uma compreensão amoldada pelo olhar adulto saudosista, revelador de uma infância idealizada.

Era claro o desejo da criança de ser reconhecida como madura, "crescida". Exemplo é a referência constante à troca da dentição e ao fato de conseguirem realizar sozinhas tarefas como carregar a mochila ou de não chorar em situações de tensão. Mesmo entre as crianças com 5 e 6 anos, um grupo significativo referia-se à infância no tempo pretérito: "Atirei um pau no gato é música de criancinha"; "Eu vejo novela desde que eu era criança"; "Quando eu era criança eu gostava do Bob Esponja".

Essa diversidade de discursos - do mercado, das crianças, da mídia e dos adultos - aponta para a necessidade de se voltar à questão mesma da infância 
(e, junto desta, da vida adulta), construindo uma reflexão que incorpore a perspectiva infantil, sem abdicar de nossa presença adulta na construção dessa perspectiva. Mais do que mapear a especificidade da infância ou tratá-la como "diferente", nossa intenção é trazer à tona a alteridade, elemento central na constituição da relação adulto-criança.

São, portanto, relações pautadas no dialogismo e na alteridade que marcam a concepção e a metodologia da pesquisa com crianças que relatamos. As relações entre crianças e adultos na cultura contemporânea discutidas aqui não se limitam às que se dão no interior da família, da escola ou outros espaços sociais, mas remetem também àquelas vividas no contexto da pesquisa propriamente dito.

Por isso, não são raros os momentos em que o adulto, na condição de pesquisador, se esforça por olhar para seus atos e discursos como acontecimentos vivos, que se transformam diante do outro-criança. Da mesma forma, as experiências das crianças são confrontadas e alteradas por nossa presença, em atos e palavras. A recusa de se colocar fora da relação com a criança, sem com isso deixar de olhá-la de um outro lugar e permitir-se ser olhado por ela a partir do lugar que ocupa, é o que define essa perspectiva metodológica que conjuga produção de conhecimento e intervenção.

Essa perspectiva metodológica que conjuga conhecimento e intervenção pode ser explicitada na seguinte situação vivida no contexto de campo:

As crianças brincavam, recriando o enredo da novela "Da cor do pecado" e distribuíam entre si os personagens de uma família de lutadores, núcleo da novela que, dada sua abordagem cômica, chamava a atenção das crianças. Esse núcleo era constituído pela mãe, chamada de Mamuska, os seus três filhos e sua nora, Tina, grávida de um dos filhos de Mamuska e que é chamada por todos de "Cachorra". Daiane (5 anos), que na brincadeira representava a personagem Tina, com uma bola sob a blusa para atestar sua "gravidez", reclamava que seus colegas a estavam chamando de Tina, e não de "cachorra", como o enredo previa. Fingindo espanto, a pesquisadora pergunta à Daiane se ela é uma cachorra e, tentando entrar/subverter a brincadeira, pergunta se ela está com fome e se quer ração. Daiane logo me explica que não é cachorra no sentido de "animal". "É porque a Tina ficou com os três irmãos e agora está grávida e não sabe quem é o pai. Por isso que chamam a Tina de cachorra". Meio atônita, a pesquisadora 
pensa em alguma coisa para perguntar, que evoque a opinião das crianças sobre a brincadeira, mas é imediatamente interrompida por Daiane, que completa a história com muita naturalidade dizendo: "- e nem adianta fazer DNA, porque eles são irmãos, então não vai saber mesmo...". A pesquisadora ficou sem saber se continuava tentando elaborar uma pergunta e ao mesmo tempo refletindo sobre esse caso do DNA, sobre o qual nunca havia pensado. E antes que pudesse tomar qualquer atitude, as crianças prosseguiram sua brincadeira, com Daiane (ou melhor, a personagem Tina) correndo atrás dos meninos, chamando-os para tomar uma sopa e sendo xingada: "Sai, Cachorra, sai Cachorra". Num outro dia, quando a pesquisadora tenta voltar ao assunto, Daiane não dá muita conversa, limitando-se a dizer: "Você gostou daquela brincadeira, né?". ${ }^{4}$

A descrição da cena, observada em campo e detalhada no "diário de bordo" da pesquisadora, traz uma infinidade de questões para o tema da pesquisa com crianças. A primeira diz respeito à percepção das diferenças entre os sentidos produzidos pelas crianças quando assistem às novelas, em comparação com os sentidos que os adultos produzem sobre a mesma cena. Não há discurso sem julgamento de valor, e nesse relato fica evidente que adultos e crianças negociam valores distintos sobre o sentido da palavra "cachorra". Nessa arena de negociação de sentidos, a criança de cinco anos desconhece o relato de outros possíveis sentidos para a palavra "cachorra", e mostra com naturalidade que para ela "cachorra" significa "namoradeira" e ponto final.

Para o pesquisador, trata-se de procurar entender, a partir do ângulo da criança, o que de fato ela está dizendo, sem colocar a sua interpretação como sendo a dela. Isso requer um reconhecimento dos limites do discurso e a consciência de que para alcançar a verdadeira compreensão deve abrir mão do seu ponto de vista, ou seja, do seu julgamento. Só assim poderá se aproximar da experiência singular que o outro nos proporciona através do seu discurso. Nessa troca, a criança também começa a perceber a diversidade dos sentidos das palavras e a construir uma compreensão mais crítica sobre os limites e possibilidades do dizer no campo social.

4. Esse relato faz parte dos registros do diário de campo. Mostra a tensão que se estabelece no diálogo entre crianças e adultos em busca de uma compreensão comum de cenas divulgadas na mídia. Destacamos a ambiguidade que se revela no uso das palavras e como os sentidos se fazem e se desfazem por meio do uso ordinário da língua no âmbito da pesquisa. 
As fronteiras entre crianças e adultos, como salienta Buckingham (2000), são desenhadas e redesenhadas, ao passo que a arena simbólica em que estas se constituem também vai assumindo novas facetas. Definir categoricamente o que pertence ao mundo da infância e ao mundo adulto significa tratar as experiências e relações entre crianças e adultos como acontecimentos apartados das transformações que movimentam a vida social e cultural. Com isso, o autor admite que a ideia do desaparecimento da infância na cultura contemporânea, defendida por Postman, carrega conceitos de infância e vida adulta que se fixam às práticas culturais do tempo em que são forjadas.

A ausência de segredos e pudor na relação entre crianças e adultos, o convívio e o envolvimento das crianças em assuntos como violência e sexo, ao mesmo tempo em que derrubam as barreiras antes existentes entre a infância e a vida adulta, apontam para outras configurações desses mundos. Diante das experiências e práticas sociais que hoje crianças e adultos compartilham, há muito mais a construção de outros sentidos e imagens sobre o mundo da infância do que sua derrocada. As relações estabelecidas entre crianças e adultos, em cada tempo e cultura, recriam e redefinem permanentemente fronteiras entre a infância e a vida adulta.

As figuras de Górgonas, Dionísio e Ártemis nos permitem ampliar as fronteiras da imaginação e criar novas estratégias para avaliarmos as dificuldades enfrentadas na relação com o outro, especialmente quando reconhecemos os jogos de identidades que se colocam como opções na vida, mas também para o pesquisador das humanidades. Como metáforas do olhar e da escuta do outro, as três figuras mitológicas despertam a consciência para a difícil tarefa que é o ato de viver e para a responsabilidade na condução das nossas escolhas diárias.

Tomar a cena da pesquisa como um ato na vida é um modo de ampliar a consciência de estar no mundo. Já dissemos anteriormente, e assinalamos mais uma vez, que o outro, na relação entre pesquisador e criança, ainda que reconhecidamente outro, pode se apresentar como ameaça, como indagação, como procura ou complemento.

Cabe ao pesquisador ampliar seus modos de ver e de interpretar o que cada conjunto de narrativas, no âmbito da pesquisa, revela sobre a relação do adulto com a criança naquele contexto específico, para, em seguida, estabelecer relações mais amplas, que extrapolam a cena particular e estão presentes no mundo contemporâneo. 
Em outras palavras, o particular, as narrativas que acontecem no cotidiano sugerem pontos de encontro com a totalidade da experiência do homem contemporâneo. Nesse ir e vir da parte para o todo e do todo para as particularidades, a história do homem de faz e se refaz.

Parafraseando Mikhail Bakhtin (2003), em seu pequeno e intenso texto intitulado "Arte e Responsabilidade", terminamos este artigo afirmando que a pesquisa e a vida não são a mesma coisa, mas devem se tornar algo singular para o pesquisador, no exato momento da revelação de sua responsabilidade e compromisso únicos com o devir.

\section{REFERÊNCIAS BIBLIOGRÁFICAS}

AMORIM, M. O Pesquisador e seu outro: Bakhtin nas ciências humanas. São Paulo: Musa, 200 I. BAKHTIN, M. Estética da criação verbal. São Paulo: Martins Fontes, 2003.

BUCKINGHAM, D. After the death of childhood: growing up in the age of electronic media. Cambridge: Polity Press, 2000.

FREITAS, M. T.; SOUZA, S. J. e; KRAMER, S. (orgs.) Ciências humanas e pesquisa: leituras de Mikhail Bakhtin. 2.ed. São Paulo: Cortez, 2007.

POSTMAN, N. O Desaparecimento da infância. Rio de Janeiro: Graphia, 1999.

SOUZA, S. J. e. Infância e linguagem. I0. ed. Campinas: Papirus, 2005.

SOUZA, S. S. J. e; CASTRO, L. R. Pesquisando com crianças: subjetividade infantil, dialogismo e gênero discursivo. Psicologia Clínica, v.9, n.9, p.83-1 I 5, 1998.

VERNANT, J. P. La Mort dans les yeux: figure de l'autre dans la Grèce Ancienne. Paris: Hachette, 1985.

. O Universo, os deuses e os homens. São Paulo: Companhia das Letras, 2005.

Recebido em: dezembro 2007

Aprovado para publicação em: setembro 2008 